Discussion Paper No. 860

\title{
INFRASTRUCTURE UPGRADES \\ AND FORECLOSURE \\ WITH COEXISTENCE OF SERVICE-BASED \\ AND FACILITY-BASED FIRMS
}

\author{
Noriaki Matsushima \\ Keizo Mizuno
}

December 2012

The Institute of Social and Economic Research

Osaka University

6-1 Mihogaoka, Ibaraki, Osaka 567-0047, Japan 


\title{
Infrastructure Upgrades and Foreclosure with Coexistence of Service-Based and Facility-Based Firms
}

\author{
Noriaki Matsushima* \\ Institute of Social and Economic Research, Osaka University \\ Keizo Mizuno \\ School of Business Administration, Kwansei Gakuin University
}

December 9, 2012

\begin{abstract}
We investigate the incentives for facility-based firms to invest in infrastructure upgrades and to foreclose service-based firms. We focus on asymmetric regulation regarding servicebased firms' access to the infrastructure held by a facility-based firm. Spillovers from the infrastructure upgrades made by a regulated facility-based firm on service-based firms play a key role in the incentives for making these upgrades. The spillover effect can enhance the incentives for the regulated facility-based firm to make upgrades if access prices are not regulated. The existence of rival facility-based firms strengthens the incentives for a regulated facility-based firm to make infrastructure upgrades, especially when the spillover effect is significant. Furthermore, if access prices are not regulated, the existence of rival facility-based firms weakens the incentives for a regulated facility-based firm to foreclose service-based firms.
\end{abstract}

Keywords: investment, access, service-based firm, facility-based firm.

JEL classification: L43, L51, L96.

\footnotetext{
*Corresponding author: Noriaki Matsushima, Institute of Social and Economic Research, Osaka University, Mihogaoka 6-1, Ibaraki, Osaka 567-0047, Japan. Phone: +81-6-6879-8571. E-mail: nmatsush@iser.osaka-u.ac.jp
} 


\section{Introduction}

High-quality networks that allow high-speed Internet access, such as Next Generation Networks, are a driving force of economic growth in many countries and in the world as a whole. ${ }^{1}$ Different countries have adopted different policy approaches for infrastructure upgrades (or broadband penetration) and the promotion of competition in telecommunications. In the US, the deregulation of telecommunications is considered to be an effective tool for incentivizing infrastructure upgrades and promoting competition, whereas in Korea and Japan, the government intervenes directly. The EU takes an intermediate stance, and its policy remains under debate. ${ }^{2}$ Some intrinsic characteristics of these countries, such as technological progress in telecommunications and political or bureaucratic systems, affect whether deregulation or intervention is a better way to enhance infrastructure upgrades.

The main purpose of this paper is to examine the incentives for facility-based firms to upgrade their infrastructure and foreclose other firms. We take into account the coexistence of servicebased firms that need to pay an access charge to borrow the infrastructure held by a facilitybased firm (call this facility-based firm the incumbent) and facility-based firms that can serve consumers using their own infrastructure (so-called bypass). Allowing these firms to coexist gives policymakers the option to impose "asymmetric access regulation" on a dominant incumbent firm. Access regulation is asymmetric if a dominant incumbent firm is obligated to provide access to service-based firms but other facility-based firms are not required to do so. ${ }^{3}$

It is important to investigate the effect of asymmetric access regulation in a real policy arena because many countries, including the US, the EU countries, Korea, and Japan, have adopted such regulations in their telecommunication sectors. For example, in the US, the local loop unbundling under the 1996 Telecommunications Act obligates telephone companies to provide

\footnotetext{
${ }^{1}$ See Crandal (2005) and Hatfield et al. (2005) for information on the effect of the penetration of broadband networks on the economy as a whole.

${ }^{2}$ For example, see Huigen and Cave (2008), Picot and Wernick (2007), and de Bijl and Peitz (2008) for the regulatory approaches in several developed countries.

${ }^{3}$ We use the term, "asymmetric access regulation," to refer to the situation where access regulation is imposed only on the dominant firm to facilitate the entry of independent service-based firms. This term is different from that in Peitz (2005a,b), who investigates access regulation in the context of two-way access.
} 
access, but it does not affect cable TV companies, which also are facility-based firms. This is a typical example of asymmetric access regulation, and service-based and facility-based firms coexist under this type of regulation. The EU, Korea, and Japan have also set such asymmetric access regulations. ${ }^{4}$

Under asymmetric access regulation, the dominant incumbent firm's freedom to set its access price significantly affects its incentives to make infrastructure upgrades or foreclose servicebased firms. When access price regulation is imposed on the dominant incumbent firm, its incentives to make infrastructure upgrades fall because these upgrades also benefit the servicebased firms that use the infrastructure and are its rivals in the retail market. On the contrary, when the dominant incumbent firm freely sets the access price for service-based firms, it can indirectly control the service-based firms in the retail market through an optimal combination of infrastructure upgrades and the access price. In particular, the incumbent may accommodate other firms as its de facto affiliates to earn profits from the access charge. ${ }^{5}$

Furthermore, strategic interactions between the incumbent and other facility-based firms through investments in infrastructure upgrades also play a key role in this setting. To fully understand the effect of access price regulation on the market, we need to know how asymmetric access regulation and access price regulation affect the incentives of all facility-based firms, including the dominant incumbent firm. We therefore analyze the performance of those regulations by considering the incentives of all facility-based firms to invest in infrastructure upgrades and foreclose service-based firms.

From the analysis in this paper, we derive four main results, which can be explained by spillovers from the usage of the incumbent's infrastructure. First, the spillover effect weakens the incumbent's incentives to make infrastructure upgrades if access price regulation is imposed

\footnotetext{
${ }^{4}$ Hoernig (2011) investigates the effect of asymmetric access regulation on the market environment when the market consists of two service-based firms and two facility-based firms, but he does not take into account infrastructure upgrades. Asymmetric regulation in his model means that only one of the facility-based firms has an obligation to allow service-based firms to use its facility, whereas under symmetric regulation, each facility-based firm has that obligation.

${ }^{5}$ Of course, the incumbent may foreclose service-based firms from the market by setting a significantly high access price if it is allowed to set its access price freely.
} 
on the incumbent. On the contrary, this effect can enhance the incentives of the incumbent to make infrastructure upgrades if access price regulation is not imposed. Second, the existence of another facility-based firm strengthens the incumbent's incentives to make infrastructure upgrades, especially when the spillover effect is large. Third, the existence of another facilitybased firm weakens the incumbent's incentives to foreclose a service-based firm even when there is no access price regulation. Fourth, the incumbent has more incentives to invest in infrastructure upgrades without access price regulation than with it. On the contrary, another facility-based firm can have more incentives to make infrastructure upgrades with access price regulation. This last result is explained by the relative magnitude of the spillover effect and the strategic effect of these investments.

In contrast to this paper, the existing literature on the relationship between access price regulation and infrastructure investment focuses on the duopoly consisting of a vertically integrated incumbent and a service-based entrant firm. ${ }^{6}$ Foros (2004) and Kotakorpi (2006) examine the effect of access price regulation on an incumbent's incentive to invest in infrastructure upgrades and to foreclose an entrant. Bourreau and Doğan (2004) demonstrate the incumbent's strategic incentive to delay a facility-based entry by providing attractive terms of access to its infrastructure. ${ }^{7}$ Although recent studies by Bourreau et al. (2011) and Bender and Götz (2011) explicitly deal with an entrant's incentives with respect to the make-or-buy decision, they do not consider the effect of asymmetric access regulation when two types of non-incumbent firms coexist in the market.

Section 2 describes the framework of the model. Section 3 analyzes the model, compares different regimes under asymmetric access regulation, and derives the results regarding a firm's incentives to make infrastructure upgrades or foreclose service-based firms. Section 4 gives concluding remarks.

\footnotetext{
${ }^{6}$ For a survey on the relationship between access regulation and infrastructure investment, see Guthrie (2006) and Cambini and Jiang (2009).

${ }^{7}$ See also Gans (2001) and Gans and King (2004) for a policy design that promotes infrastructure investment in a duopoly.
} 


\section{Model}

There are two vertically related sectors in the market: an upstream sector and a downstream sector. These two sectors are required to supply services to consumers. We assume that there are three firms of different types: firm $I$, firm $S$, and firm $F$. The market structure we examine in this paper is asymmetric in the sense that the market positions of firms $I$ and $F$ are different from each other. Firm I, the incumbent, has infrastructure upstream and a production facility downstream (i.e., it is a vertically integrated firm). Firm $S$, a service-based firm, is a potential entrant that has only a production facility downstream. To serve consumers, firm $S$ needs to access firm $I$ 's infrastructure by paying usage access charge $a$ to firm $I$. In other words, firm $I$ is obligated to give access to a potential entrant that requires it. Firm $F$, called a facility-based firm, is a vertically integrated firm that owns its infrastructure but is not obligated to give access to firm $S$. That is, the difference between firm $F$ and firm $I$ is that only firm $I$ is required to provide access to its infrastructure to firm $S$. In this sense, access regulation is asymmetric. This assumption reflects asymmetric access regulation found in policies in the EU, the US, Korea, and Japan. In our model, only the service-based firm (i.e., firm $S$ ) is assumed to be a potential entrant. This assumption is justified by the fact that a service-based firm has no infrastructure upstream, so it does not incur a large sunk cost for entry and exit.

One unit of input produced upstream produces one unit of output downstream. We assume that the constant marginal access cost $c$ that firm $I$ must pay to give firm $S$ access is the same as its marginal production cost upstream and that the production cost downstream for each firm is zero. For simplicity, we also assume that the production cost of firm $F$ is exactly the same as that of firm $I$.

The two vertically integrated firms, $I$ and $F$, have the opportunity to make investments to upgrade their own infrastructure. These investments have a demand-enhancing effect because they improve the quality of services sold downstream. A typical example would be an investment in broadband technology, such as FTTH, that upgrades the speed or quality of information 
searches and thus would enhance consumer demand.

The utility function of a representative consumer is given as

$$
U=v_{I} q_{I}+v_{F} q_{F}+v_{S} q_{S}-\frac{\left(q_{I}+q_{F}+q_{S}\right)^{2}}{2}+m
$$

where $v_{j}$ represents the quality of service $j(j=I, F, S), q_{j}$ is the quantity supplied by firm $j$ $(j=I, F, S)$, and $m$ is a numéraire good. The inverse demand function for each service is given as $(j=I, F, S)$

$$
p_{j}=v_{j}-Q
$$

where $Q \equiv q_{I}+q_{F}+q_{S}$. The net consumer surplus is given as

$$
C S=\frac{\left(q_{I}+q_{F}+q_{S}\right)^{2}}{2}=\frac{Q^{2}}{2}
$$

We examine different regimes based on each firm's ability to upgrade its infrastructure and determine its access charge. In particular, we deal with three innovation regimes: (1) only firm $I$ is able to invest in upgrading its infrastructure, (2) only firm $F$ is able to invest in upgrading its infrastructure, and (3) both firms $I$ and $F$ are able to invest in upgrading their infrastructures. As shown below, this step-by-step approach helps to illustrate the different incentives for firms $I$ and $F$, which face different access regulations, to invest in infrastructure. Then, we examine the effect of access price regulation under each of three innovation regimes. To do so, we compare the "access price regulation regime," in which a regulator determines the level of access charge $a$, and the "no access price regulation regime," in which firm $I$ unilaterally determines the level of $a$. Notice that even in a no access price regulation regime, firm $I$ is obligated to provide access to firm $S$, whereas firm $F$ is not.

In sum, we have the following six regimes. 


\begin{tabular}{||c||c||c||c||}
\hline \hline Access \Innovation regime & firm $I$ & firm $F$ & firms $I \& F$ \\
\hline \hline Access price regulation $R$ & $R I$ & $R F$ & $R I F$ \\
\hline \hline No access price regulation $N$ & $N I$ & $N F$ & $N I F$ \\
\hline \hline
\end{tabular}

Then, in each of six regimes, the qualities of the services and the investment costs are given by

$$
v_{I}=\alpha+\delta_{I} x_{I}, v_{F}=\alpha+\delta_{F} x_{F}, v_{S}=\alpha+s \delta_{I} x_{I}, I\left(x_{j}\right)=\frac{\gamma x_{j}^{2}}{2}
$$

where $\alpha(>c)$ is a positive constant that can be interpreted as consumers' willingness to pay for a service supplied by an old infrastructure, $x_{j}(j=I, F)$ is the investment level of firm $j, s$ is the degree of spillovers from firm $I$ to firm $S$ due to the required access, and $\gamma(>0)$ is the investment technology parameter of firms $I$ and $F$. We use the same investment technology for firms $I$ and $F$ for analytical simplicity. $\delta_{j} \in\{0,1\}$ indicates whether or not firm $j(=I, F)$ is able to invest in infrastructure. Thus, we can represent different innovation regimes in a compact way. The degree of spillover, $s$, reflects the relative inferiority or superiority of firm $S$ 's retail production technology as compared to that of firm $I$ under the upgraded infrastructure.

In the following analysis, we restrict our attention to the case in which firm $S$ 's retail production technology is inferior (or at best identical) to that of firm $I, s \in[0,1]$. As will be shown in the analysis, however, the results derived for the case in which $s>1$ are qualitatively similar to those for the case in which $s=1$. This restriction is justified by firm I's better ability to obtain knowledge about the new infrastructure or by the regulators' mandating access differently between mature and new infrastructures.

Furthermore, we deal with firm $I$ (an incumbent) and firm $F$ (a facility-based firm) symmetrically in terms of their production and investment technologies. In a real policy arena, imposing asymmetric access regulations is usually justified by an incumbent's dominant position caused by its better technology. However, including these asymmetries between firms $I$ and $F$ makes the analysis too complicated. We think that a benefit of the symmetric treatment is that we can clearly examine the effect of imposing access obligations on an incumbent. We also think 
that our results do not qualitatively change even if we take into account these technological asymmetries.

To preserve analytical tractability, we make the following assumptions.

Assumptions (i) $a \geq c$, (ii) $\gamma>3 / 2$.

Assumption (i) is set for practical reasons. ${ }^{8}$ In fact, it is rare for access charges to be set below the marginal access cost in the real world. Assumption (ii) guarantees interior solutions not only for firm I's profit-maximizing investment problem but also for the regulator's welfare-maximizing investment problem, as shown in the following analysis.

The market structure in this model is depicted in Figure 1.

[Figure 1 here]

The timing of the game is as follows. In each of the six regimes, the investment stage comes first, because investments are irreversible and the ability to commit to an access charge is limited. In the second stage, given the level of investment, the access charge $a$ is determined. In the third stage, firm $S$ decides whether to enter the market with access or not. In the fourth stage, all active firms compete downstream in a Cournot fashion.

\section{Analysis}

\subsection{Preliminary result: the outcome in the fourth stage}

In each of the six scenarios, the profit functions of the firms are given by

$$
\begin{aligned}
& \pi_{I}=\left(p_{I}-c\right) q_{I}+(a-c) q_{S}-\delta_{I} I\left(x_{I}\right), \\
& \pi_{F}=\left(p_{F}-c\right) q_{F}-\delta_{F} I\left(x_{F}\right) \\
& \pi_{S}=\left(p_{S}-a\right) q_{S}
\end{aligned}
$$

\footnotetext{
${ }^{8}$ This assumption also appears in Foros (2004).
} 
Here, we assume that firm $S$ 's sunk cost of entry is zero.

If $S$ enters in the third stage, there is a triopoly in the fourth stage. Solving the maximization problems of the firms, we have

$$
\begin{aligned}
& q_{I}\left(x_{I}, x_{F} ; a\right)=\frac{\alpha-2 c+a+(3-s) \delta_{I} x_{I}-\delta_{F} x_{F}}{4}, \\
& q_{F}\left(x_{I}, x_{F} ; a\right)=\frac{\alpha-2 c+a-(1+s) \delta_{I} x_{I}+3 \delta_{F} x_{F}}{4}, \\
& q_{S}\left(x_{I}, x_{F} ; a\right)=\frac{\alpha+2 c-3 a-(1-3 s) \delta_{I} x_{I}-\delta_{F} x_{F}}{4}, \\
& Q\left(x_{I}, x_{F} ; a\right)=\frac{3 \alpha-2 c-a+(1+s) \delta_{I} x_{I}+\delta_{F} x_{F}}{4} .
\end{aligned}
$$

If the degree of spillover $s$ is larger than $1 / 3$, firm $I$ 's investment increases firm $S$ 's quantity produced downstream. From (1) to (5), the equilibrium profits in the subgame of the fourth stage are given by

$$
\begin{aligned}
& \pi_{I}\left(x_{I}, x_{F} ; a\right)=q_{I}\left(x_{I}, x_{F} ; a\right)^{2}+(a-c) q_{S}\left(x_{I}, x_{F} ; a\right)-\delta_{I} I\left(x_{I}\right), \\
& \pi_{F}\left(x_{I}, x_{F} ; a\right)=q_{F}\left(x_{I}, x_{F} ; a\right)^{2}-\delta_{F} I\left(x_{F}\right), \\
& \pi_{S}\left(x_{I}, x_{F} ; a\right)=q_{S}\left(x_{I}, x_{F} ; a\right)^{2} .
\end{aligned}
$$

If firm $S$ does not enter the market, there is a duopoly in the fourth stage. The equilibrium quantities supplied by firms $I$ and $F$ are given by

$$
\widetilde{q}_{I}\left(x_{I}, x_{F}\right)=\frac{\alpha-c+2 \delta_{I} x_{I}-\delta_{F} x_{F}}{3}, \quad \widetilde{q}_{F}\left(x_{I}, x_{F}\right)=\frac{\alpha-c+2 \delta_{F} x_{F}-\delta_{I} x_{I}}{3} .
$$

From (9), the equilibrium profits in the subgame are given by

$$
\widetilde{\pi}_{I}\left(x_{I}, x_{F}\right)=\widetilde{q}_{I}\left(x_{I}, x_{F}\right)^{2}-\delta_{I} I\left(x_{I}\right), \quad \widetilde{\pi}_{F}\left(x_{I}, x_{F}\right)=\widetilde{q}_{F}\left(x_{I}, x_{F}\right)^{2}-\delta_{F} I\left(x_{F}\right) .
$$




\subsection{Regimes under access price regulation}

We first consider the three access price regulation regimes in which the access price for firm $S$ is set by a benevolent regulator. We verify that foreclosure does not occur in the third stage of each of the three regimes as long as the cost-based access charge (i.e., $a=c$ ) is set by the regulator. Indeed, we can ensure that in the second stage, the regulator sets the cost-based access charge if $\alpha$ is sufficiently large. ${ }^{9}$

We in turn investigate the decisions of firms $I$ and $F$ in the first stage. From (6), (7), and the fact that firm $S$ 's entry is accommodated under $a=c$, the net profits of firms $I$ and $F$ are given by

$$
\begin{aligned}
& \pi_{I}\left(x_{I}, x_{F} ; c\right)=q_{I}\left(x_{I}, x_{F} ; c\right)^{2}-\delta_{I} I\left(x_{I}\right), \\
& \pi_{F}\left(x_{I}, x_{F} ; c\right)=q_{F}\left(x_{I}, x_{F} ; c\right)^{2}-\delta_{F} I\left(x_{F}\right) .
\end{aligned}
$$

The maximization problems of firms $I$ and $F$ lead to the reaction functions

$$
\begin{gathered}
\frac{\partial \pi_{I}\left(x_{I}, x_{F} ; c\right)}{\partial x_{I}}=0 \Rightarrow x_{I}\left(x_{F}\right)=\frac{\delta_{I}(3-s)\left(\alpha-c-\delta_{F} x_{F}\right)}{8 \gamma-(3-s)^{2} \delta_{I}} \\
\frac{\partial \pi_{F}\left(x_{I}, x_{F} ; c\right)}{\partial x_{F}}=0 \Rightarrow x_{F}\left(x_{I}\right)=\frac{3 \delta_{F}\left(\alpha-c-(1+s) \delta_{I} x_{I}\right)}{8 \gamma-9 \delta_{F}}
\end{gathered}
$$

The spillover effect represented by $s$ directly weakens the incentives for firm $I$ to invest. The reaction function of firm $I$ moves downward as the degree of spillover increases (see (12)) because the spillover effect helps firm $S$, which is a competitor of firm $I$. The spillover effect also indirectly weakens the incentives for firm $F$ to invest. The reaction function of firm $F$ steepens as $s$ increases (see (13)) because the spillovers to firm $S$ weaken the strategic position of firm $F$ in the downstream sector. Note that the spillover effect does not always diminish firm $F$ 's investment level.

\footnotetext{
${ }^{9}$ In the case where $\alpha$ is not sufficiently large but firm $I$ still obtains positive profits after investments, the optimal access charge set by a regulator can be higher than the access cost when the degree of the spillover is small. See Mizuno and Yoshino (2011) for this point.
} 
Solving the simultaneous equations, we have

$$
\begin{aligned}
x_{I}^{*} & =\frac{\delta_{I}(3-s)\left(2 \gamma-3 \delta_{F}\right) A}{16 \gamma^{2}-2\left(9 \delta_{F}+(3-s)^{2} \delta_{I}\right) \gamma+3(3-s)(2-s) \delta_{I} \delta_{F}}, \\
x_{F}^{*} & =\frac{3 \delta_{F}\left(2 \gamma-(3-s) \delta_{I}\right) A}{16 \gamma^{2}-2\left(9 \delta_{F}+(3-s)^{2} \delta_{I}\right) \gamma+3(3-s)(2-s) \delta_{I} \delta_{F}},
\end{aligned}
$$

where $A \equiv \alpha-c$. Note that $x_{I}^{*}$ and $x_{F}^{*}$ hold for each of the three access price regulation regimes (i.e., $R I, R F$, and $R I F$ ) because of the indicator $\delta_{j} \in\{0,1\}$, where $j=I, F$. We now compare the three innovation regimes under access price regulation.

Proposition 1 In the access price regulation regimes in which a benevolent regulator sets the access charge (i.e., regimes $\mathrm{RI}, \mathrm{RF}$, and $\mathrm{RIF}$ ), the following hold in equilibrium:

(i) Foreclosure does not occur in any of the three innovation regimes.

(ii) $x_{I}^{* R I} \leq x_{F}^{* R F}$. The inequality holds as an equality if and only if $s=0$.

(iii) $x_{I}^{* R I F} \leq x_{F}^{* R I F}$. The inequality holds as an equality if and only if $s=0$.

(iv) $\partial x_{I}^{* R I F} / \partial s<0$ for any $s \in[0,1] . \partial x_{F}^{* R I F} / \partial s>0$ if and only if

$$
\begin{cases}s>3-2 \gamma+2 \sqrt{\gamma(\gamma-2)} & \text { if } \gamma>9 / 4 \\ s \geq 0 & \text { if } \gamma \leq 9 / 4\end{cases}
$$

Proof. See Appendix.

[Table 1 here]

The result in (i) is natural. As long as $\alpha$ (i.e., consumers' willingness to pay for a service supplied using an old infrastructure) is sufficiently large, the regulator has an incentive to set a cost-based access charge $\left(a^{*}=c\right)$ to induce competition in the downstream sector and promote a so-called level-playing field.

The results in (ii) and (iii) stem from the existence of spillovers. Indeed, firm I's investments create spillovers, whereas firm $F$ 's do not. Then, because firm $I$ is unwilling to help firm $S$ 
through these spillovers, firm $I$ has less incentive to invest in infrastructure than firm $F$ if $s \neq 0 .^{10}$

The result in (iv) represents the strategic interactions between firms $I$ and $F$. Because the strategic interactions between firms $I$ and $F$ are strategic substitutes (see (12) and (13)), the direct negative effect of spillovers on firm $I$ 's incentives to invest enhances firm $F$ 's incentives to invest. When the investment cost $\gamma$ is smaller, the incentives for firms to invest are larger, which implies that the negative spillover effect on firm $I$ is also larger. Therefore, when the degree of spillovers $s$ is large or when the investment technology is efficient ( $\gamma$ is small), this strategic effect of spillovers on firm $F$ dominates their indirect negative effect (see (13)).

Table 1 summarizes the conditions for accommodating firm $S$ 's entry, a vertically integrated firm's innovation incentive, and the equilibrium access charge in each of the three access price regulation regimes, $R I, R F$, and $R I F$. The table also gives the result in Foros (2004), called regime $R$, as a benchmark. This regime is similar to $R I$ except that firm $F$ exists in $R I$. Comparing the results of regime $R I$ and regime $R$ gives the effect of the existence of a facility-based firm, which is stated in the following proposition.

Proposition 2 Suppose that a benevolent regulator sets the access charge. Firm I engages in a higher level of investment in regime $\mathrm{RI}$ than in regime $\mathrm{R}$ if $s \geq 5 / 7$ or if $\gamma<2(3-s)(2-$ $s) /(5-7 s)$ and $s<5 / 7$. Otherwise, firm I engages in a lower level of investment in regime RI than in regime $\mathrm{R}$.

Proof. See Appendix.

We next discuss how the degree of spillovers affects the gain from investment in infrastructure. The marginal gain and loss from investment are given by

$$
\frac{\partial \pi_{I}}{\partial x_{I}}=\underbrace{p_{I}^{\prime} q_{I} \sum_{i \in H} \frac{\partial q_{i}}{\partial x_{I}}}_{\text {strategic effect }}+\underbrace{q_{I}}_{\text {quality improvement effect }}-I^{\prime}\left(x_{I}\right),
$$

\footnotetext{
${ }^{10}$ It is obvious that $x_{j}^{* R j}>x_{j}^{* R I F}(j=I, F)$. This is because firms' investments are strategic substitutes for each other.
} 
where $H$ is the set of $I$ 's rival firms. The first term represents the strategic effect, i.e., the marginal gain from the decrease in the rival firms' production, whereas the second term represents the quality improvement effect, i.e., the marginal gain from the improvement of product quality, and the last term is the marginal cost of investment.

We can explain how the spillover effect affects the gain from investment through the strategic effect and the quality improvement effect. In regime $R I, H=\{S, F\}$, whereas in regime $R$, $H=\{S\}$. The number of rival firms, $\# H$, is larger in regime $R I$. This implies that the marginal effect of investment on the total quantity of rival firms is larger in regime $R I$ because this total quantity is larger when the number of rival firms is larger. Moreover, the spillovers benefit firm $S$ but harm firm $F$ because only firm $S$ benefits from firm $I$ 's investment. Therefore, the negative effect of spillovers on firm $I$ is weaker in regime $R I$ because the negative effect of these spillovers on firm $F$ mitigates the direct negative effect of spillovers on firm $I$ in regime $R I$. From these two factors, we can conclude that the strategic effect is stronger in regime $R I$ and that the difference in the size of this effect between the two regimes increases with the degree of spillovers. On the other hand, the quality improvement effect is stronger in regime $R$ because downstream competition in this regime is milder. Which of the strategic and the quality improvement effects is stronger depends on the degree of spillovers.

The following equations help us to discuss how the two effects depend on the degree of spillovers.

$$
\begin{aligned}
M R_{I}^{R} & =\frac{(1-2 s)\left(A+(2-s) x_{I}\right)}{9}+\frac{A+(2-s) x_{I}}{3}=\frac{2(2-s) A+2(2-s)^{2} x_{I}}{9}, \\
M R_{I}^{* R I} & =\frac{(1-s)\left(A+(3-s) x_{I}\right)}{8}+\frac{A+(3-s) x_{I}}{4}=\frac{(3-s) A+(3-s)^{2} x_{I}}{8},
\end{aligned}
$$

where $M R_{I}^{R}$ is firm $I$ 's marginal gain from investment in regime $R$ and $M R_{I}^{* R I}$ is firm $I$ 's marginal gain from investment in regime $R I$. The left panel of Figure 2 shows equilibrium investments in regime $R I$ and in regime $R$ for $s=0$.

[Figure 2 here] 
When $s=0$, the constant term is larger in regime $R$, and the slope of $x_{I}$ is steeper in regime $R I$. The latter reflects the stronger strategic effect in regime $R I$. Because the two lines intersect, we find that firm $I$ has more incentive to invest in regime $R I$ only if the investment cost is low. The right panel of Figure 2 depicts the case where $s=1$. In the panel, the marginal gain from investment in regime $R I$ shifts upwards so that firm $I$ 's incentive to invest in infrastructure is always higher in regime $R I$ than in regime $R$. This is because the strategic effect in regime $R I$ is significantly larger than that in regime $R$. The strategic effect in regime $R$ is negative because firm $I$ 's investment just helps its rival, firm $S$.

\subsection{Regimes under no access price regulation}

Next, we examine the three no access price regulation regimes, regimes $N I, N F$, and $N I F$, in which firm $I$ can unilaterally determine the level of $a$. In these no access price regulation regimes, the access charge $a$ set by firm $I$ can be an effective tool for foreclosure. One interesting question is how each innovation regime affects the effectiveness of $a$ as a foreclosure tool.

In the second stage, if firm $I$ anticipates firm $S$ 's entry, its profit is given by

$$
\pi_{I}\left(x_{I}, x_{F} ; a\right)=q_{I}\left(x_{I}, x_{F} ; a\right)^{2}+(a-c) q_{S}\left(x_{I}, x_{F} ; a\right)-I\left(x_{I}\right)
$$

The maximization problem of firm $I$ leads to the optimal access charge

$$
a\left(x_{I}, x_{F}\right)=c+\frac{3 A+(1+5 s) \delta_{I} x_{I}-3 \delta_{F} x_{F}}{11} .
$$

We discuss how the investment levels affect the access charge, $a\left(x_{I}, x_{F}\right)$.

Lemma 1 The access charge $a\left(x_{I}, x_{F}\right)$ set by firm I increases with $x_{I}$ but decreases with $x_{F}$.

Investment by firm $F$ lowers the quantities supplied by its rivals (firms $I$ and $S$ ), which in turn lowers the marginal gains of firm $I$ from its own downstream profit through the access charge (the first term in (18)) and from its access profit (the second term in (18)). Hence, 
$a\left(x_{I}, x_{F}\right)$ decreases with $x_{F}$. On the other hand, investment by firm $I$ always increases its own quantity and can lower the quantity of firm $S$. The marginal gain of firm $I$ therefore increases because the access charge prevents competition, but its marginal gain from the access profit falls. The former effect dominates the latter, and hence, $a\left(x_{I}, x_{F}\right)$ increases with $x_{F}$. Therefore, the lemma holds.

Under the access price in (19), the quantity supplied by firm $S$ is

$$
q_{S}\left(x_{I}, x_{F} ; a\left(x_{I}, x_{F}\right)\right)=\frac{A-(7-9 s) \delta_{I} x_{I}-\delta_{F} x_{F}}{22} .
$$

Given $x_{I}$ and $x_{F}$, if (20) is positive, firm $S$ enters the market in the third stage, otherwise, it does not. Note that in regime $N I\left(\delta_{I}=1\right.$ and $\left.\delta_{F}=0\right)$, when $s \geq 7 / 9, q_{S}\left(x_{I}, x_{F} ; a\left(x_{I}, x_{F}\right)\right)$ in (20) is larger than zero, so that firm $I$ certainly accommodates firm $S$ 's entry for $s \geq 7 / 9$ regardless of the level of $x_{I}$.

Lemma 2 In regime NI, firm I accommodates firm $S$ 's entry if $s \geq 7 / 9$.

If the degree of spillovers is high, firm $I$ uses firm $S$ as its affiliate to compete with firm $F$. Firm $I$ gains a profit from the access charge. This contrasts with Foros (2004), who shows that firm $I$ always forecloses firm $S$ if $s \leq 1$. The contrasting results imply that the existence of a facility-based firm mitigates the incentive for firm $I$ to foreclose firm $S$.

We next explore whether firms $I$ and $F$ have incentives to foreclose firm $S$ through their investments in equilibrium. When $q_{S}\left(x_{I}, x_{F} ; a\left(x_{I}, x_{F}\right)\right) \geq 0$, the quantities supplied by firms $I$ and $F$ are given by

$$
\begin{aligned}
q_{I}\left(x_{I}, x_{F} ; a\left(x_{I}, x_{F}\right)\right) & =\frac{7 A+(17-3 s) \delta_{I} x_{I}-7 \delta_{F} x_{F}}{22} . \\
q_{F}\left(x_{I}, x_{F} ; a\left(x_{I}, x_{F}\right)\right) & =\frac{7 A-(5+s) \delta_{I} x_{I}+15 \delta_{F} x_{F}}{22} .
\end{aligned}
$$

When $q_{S}\left(x_{I}, x_{F} ; a\left(x_{I}, x_{F}\right)\right) \leq 0$, firm $S$ is foreclosed and the competition structure becomes a 
duopoly of firms $I$ and $F$. The quantities are given as

$$
\widetilde{q}_{I}\left(x_{I}, x_{F}\right)=\frac{\alpha-c+2 \delta_{I} x_{I}-\delta_{F} x_{F}}{3}, \quad \widetilde{q}_{F}\left(x_{I}, x_{F}\right)=\frac{\alpha-c+2 \delta_{F} x_{F}-\delta_{I} x_{I}}{3} .
$$

In the first stage, firms $I$ and $F$ set their investment levels. Their maximization problems are given by

$$
\begin{gathered}
\pi_{I}\left(x_{I}, x_{F} ; a\left(x_{I}, x_{F}\right)\right)= \begin{cases}q_{I}\left(x_{I}, x_{F} ; a\left(x_{I}, x_{F}\right)\right)^{2}+(a-c) q_{S}\left(x_{I}, x_{F} ; a\left(x_{I}, x_{F}\right)\right)-\delta_{I} I\left(x_{I}\right) \\
\widetilde{q}_{I}\left(x_{I}, x_{F}\right)^{2}-\delta_{I} I\left(x_{I}\right) & \text { if } q_{S}\left(x_{I}, x_{F} ; a\left(x_{I}, x_{F}\right)\right) \geq 0,(23)\end{cases} \\
\pi_{F}\left(x_{I}, x_{F} ; a\left(x_{I}, x_{F}\right)\right)= \begin{cases}q_{F}\left(x_{I}, x_{F} ; a\left(x_{I}, x_{F}\right)\right)^{2}-\delta_{F} I\left(x_{F}\right) & \text { if } q_{S}\left(x_{I}, x_{F} ; a\left(x_{I}, x_{F}\right)\right) \leq 0 . \\
\widetilde{q}_{F}\left(x_{I}, x_{F}\right)^{2}-\delta_{F} I\left(x_{F}\right) & \text { if } q_{S}\left(x_{I}, x_{F} ; a\left(x_{I}, x_{F}\right)\right) \geq 0\end{cases}
\end{gathered}
$$

The first-order conditions lead to the following reaction functions:

$$
\begin{aligned}
& \frac{\partial \pi_{I}\left(x_{I}, x_{F} ; a\left(x_{I}, x_{F}\right)\right)}{\partial x_{I}}=0 \\
& \Rightarrow x_{I}\left(x_{F}\right)= \begin{cases}\frac{\delta_{I}(9+s)\left(A-\delta_{F} x_{F}\right)}{22 \gamma-\left(25-14 s+9 s^{2}\right) \delta_{I}} & \text { if } q_{S}\left(x_{I}, x_{F} ; a\left(x_{I}, x_{F}\right)\right) \geq 0, \\
\frac{4 \delta_{I}\left(A-\delta_{F} x_{F}\right)}{9 \gamma-8} & \text { if } q_{S}\left(x_{I}, x_{F} ; a\left(x_{I}, x_{F}\right)\right) \leq 0 .\end{cases} \\
& \frac{\partial \pi_{F}\left(x_{I}, x_{F} ; a\left(x_{I}, x_{F}\right)\right)=0}{\partial x_{F}} \\
& \Rightarrow x_{F}\left(x_{I}\right)= \begin{cases}\frac{15 \delta_{F}\left(7 A-(5+3 s) \delta_{I} x_{I}\right)}{242 \gamma-225 \delta_{F}} & \text { if } q_{S}\left(x_{I}, x_{F} ; a\left(x_{I}, x_{F}\right)\right) \geq 0, \\
\frac{4 \delta_{F}\left(A-\delta_{I} x_{I}\right)}{9 \gamma-8} & \text { if } q_{S}\left(x_{I}, x_{F} ; a\left(x_{I}, x_{F}\right)\right) \leq 0 .\end{cases}
\end{aligned}
$$

The strategic interaction between firms $I$ and $F$ in the first stage is strategic substitution. When firm $S$ is active, that is, when $q_{S} \geq 0$, firm $F$ is less aggressive due to the spillover effect of investment by firm $I$ (see (26)). On the other hand, this spillover effect enhances the incentives for firm $I$ to invest because of the access profit from firm $S$ (see (25)). This property of firm 
$I$ 's reaction function is quite different from those in regimes $R I$ and $R I F$ (see (12)). From this comparison, we easily anticipate that the effect of spillovers on the incentives of firms $I$ and $F$ in the no access price regulation regimes is quite different from that in the access price regulation regimes.

Solving the simultaneous equations, we have

$$
\begin{aligned}
x_{I}^{*} & =\frac{\delta_{I}(9+s)\left(11 \gamma-15 \delta_{F}\right) A}{242 \gamma^{2}-\left(225 \delta_{F}+11\left(25-14 s+9 s^{2}\right) \delta_{I}\right) \gamma+15\left(15-11 s+6 s^{2}\right) \delta_{I} \delta_{F}}, \\
x_{F}^{*} & =\frac{15 \delta_{F}\left(7 \gamma-\left(10-3 s+3 s^{2}\right) \delta_{I}\right) A}{242 \gamma^{2}-\left(225 \delta_{F}+11\left(25-14 s+9 s^{2}\right) \delta_{I}\right) \gamma+15\left(15-11 s+6 s^{2}\right) \delta_{I} \delta_{F}}, \\
a\left(x_{I}^{*}, x_{F}^{*}\right) & =c+\frac{2\left(3 \gamma-(3-s)(1-s) \delta_{I}\right)\left(11 \gamma-15 \delta_{F}\right) A}{242 \gamma^{2}-\left(225 \delta_{F}+11\left(25-14 s+9 s^{2}\right) \delta_{I}\right) \gamma+15\left(15-11 s+6 s^{2}\right) \delta_{I} \delta_{F}},
\end{aligned}
$$

if $q_{S}\left(x_{I}^{*}, x_{F}^{*} ; a\left(x_{I}^{*}, x_{F}^{*}\right)\right) \geq 0$. Otherwise,

$$
\widetilde{x}_{j}^{*}=\frac{4 \delta_{j} A\left(3 \gamma-4 \delta_{-j}\right)}{27 \gamma^{2}-24\left(\delta_{I}+\delta_{F}\right) \gamma+16 \delta_{I} \delta_{F}}, \quad j,-j=I, F ; j \neq-j
$$

The inequality $q_{S}\left(x_{I}^{*}, x_{F}^{*} ; a\left(x_{I}^{*}, x_{F}^{*}\right)\right) \geq 0$ holds if and only if

$$
\gamma \geq 4(1-s) \delta_{I} \equiv \bar{\gamma}
$$

The inequality $q_{S}\left(x_{I}^{*}, x_{F}^{*} ; a\left(x_{I}^{*}, x_{F}^{*}\right)\right) \leq 0$ holds if and only if

$$
\gamma \leq 4(1-s) \delta_{I} \equiv \bar{\gamma}
$$

From (30), we have the following proposition:

Proposition 3 In the no access price regulation regimes in which firm I freely sets the level of access charge a (i.e., regimes NI, NF, and NIF), the following hold in equilibrium:

(i) Firm $S$ is foreclosed if and only if $\gamma \leq \bar{\gamma}$.

(ii) Suppose that firm $S$ is accommodated in regime NI $(\gamma>\bar{\gamma})$. Then, $x_{I}^{* N I} \leq x_{F}^{* N F}$ if and 
only if

$$
\begin{aligned}
& \gamma>\frac{15\left(40-113 s+63 s^{2}\right)}{22(6-11 s)} \text { and } s \leq 6 / 11 \text { or } \\
& \gamma<\frac{15\left(40-113 s+63 s^{2}\right)}{22(6-11 s)} \text { and } 6 / 11<s<\frac{74+\sqrt{786}}{105} .
\end{aligned}
$$

On the other hand, suppose that firm $S$ is foreclosed in regime NI $(\gamma \leq \bar{\gamma})$. Then, $x_{I}^{* N I} \leq$ $x_{F}^{* N F}$ if and only if $\gamma<60 / 23$.

(iii) Suppose that firm $S$ is accommodated in regime $\operatorname{NIF}(\gamma>\bar{\gamma})$. Then, $x_{I}^{* N I F} \leq x_{F}^{* N I F}$ if and only if

$$
s \leq 6 / 11 \text { or } \gamma<\frac{15(1-s)(1-3 s)}{6-11 s} \text { and } 6 / 11<s<4 / 5
$$

On the other hand, suppose that firm $S$ is foreclosed in regime NIF $(\gamma \leq \bar{\gamma})$. Then, $x_{I}^{* N I F}=x_{F}^{* N I F}$ for any $\gamma$ and $s$.

(iv) Suppose that firm $S$ is accommodated in regime $\operatorname{NIF}(\gamma>\bar{\gamma})$. Then, $\partial x_{F}^{* N I F} / \partial s \leq 0$ for any $s$ and $\gamma . \partial x_{I}^{* N I F} / \partial s>0$ if and only if

$$
\begin{aligned}
& \gamma<\frac{943+\sqrt{475429}}{242} \text { and } s>\frac{\sqrt{(40-\gamma)(11 \gamma-10)(242 \gamma-225)}-27(11 \gamma-10)}{3(11 \gamma-10)} \\
& \text { or } \gamma \geq \frac{943+\sqrt{475429}}{242} .
\end{aligned}
$$

On the other hand, suppose that firm $S$ is foreclosed in regime NIF $(\gamma \leq \bar{\gamma})$. Then, for any $s$ and $\gamma, \partial x_{F}^{* N I F} / \partial s=0$ and $\partial x_{I}^{* N I F} / \partial s \leq 0$.

Proof. See Appendix.

[Table 2 here]

Figure 3 graphically shows the conditions of this proposition. 
[Figure 3 here]

Proposition 3(i) indicates that if the investments are not costly ( $\gamma$ is small) and the degree of spillovers is small ( $s$ is small), firm $S$ is foreclosed. The former enhances the innovation competition between firms $I$ and $F$, and the investment levels of the two firms are large. If the degree of spillovers is small, the quality difference between the two firms and firm $S$ becomes large. This means that the competitive disadvantage of firm $S$ is large if $\gamma<\bar{\gamma}$. As a result, firm $S$ is inactive if investments are not costly and the degree of spillovers is small.

The mechanism behind Proposition 3(ii) is complicated, and we separately consider two cases to explain it. First, consider the spillover effect and the strategic effect of investment in the case where firm $S$ is active $(\gamma>\bar{\gamma})$. The spillover effect increases the quantity supplied by firm $S$, which implies that firm I's gains from access revenue increase with the degree of spillovers. Hence, firm $I$ has an incentive to invest more. The white area on the right-hand side of Figure 3.1 shows this effect. The strategic effect of investment, which is shown in (17) for firm $I$ 's investment, is stronger when only firm $F$ invests than when only firm $I$ invests because investment by firm $F$ lowers the supplies of both rival firms (firms $I$ and $S$ ) whereas investment by firm $I$ lowers firm $F$ 's supply but increases firm $S$ 's supply because of the spillover effect. An investing firm's marginal gain from its investment becomes more sensitive to its investment level because of this effect, as discussed in the previous subsection (see the left panel in Figure 2 ). Because the investment level is higher when the investment cost is lower ( $\gamma$ is smaller), the strategic effect is larger when the investment cost is lower. The right-hand edge of the shaded area in Figure 3.1 reflects this property.

We return to the spillover effect. When the degree of spillovers, $s$, is small enough, the foreclosure effect of firm I's investment is stronger (the coefficient of $x_{I}$ in (20) reflects the foreclosure effect). The negative effect of firm $I$ 's investment on firm $S$ 's supply is significantly higher than that of firm $F$ 's investment (see (20)). This effect induces firm $I$ to invest more. In Figure 3.1, it is shown in the white area in the left-hand side above the line of $\gamma=\bar{\gamma}$.

Second, consider the case in which firm $S$ is inactive when firm $I$ invests $(\gamma \leq \bar{\gamma})$. The 
spillover effect does not exist in this case because firm $S$ is foreclosed. The main effect in this case is the strategic effect, as shown in (17). As explained earlier, the strategic effect is larger when the investment cost is lower. Firm $F$ 's has two rival firms under $N F$ but only one under $N I$, which implies that the strategic effect is stronger under $N F$. Therefore, firm $F$ has a stronger incentive to invest than firm $I$ when the investment cost is lower ( $\gamma$ is smaller). This is similar to the logic behind Proposition 2 (see also Figure 2).

The mechanism behind Proposition 3(iii) is basically similar to that behind Proposition 3(ii). When firm $S$ is foreclosed, firms $I$ and $F$ symmetrically compete with each other. Because of the symmetry, $x_{I}^{* N I F}=x_{F}^{* N I F}$ when $\gamma \leq \bar{\gamma}$.

The mechanism behind Proposition 3(iv) is simple. As mentioned earlier, the spillover effect enhances the incentives for firm $I$ to invest. The partial derivative reflects the effect.

Comparison between regimes $N I$ and $N$ As in the subsection on access price regulation regimes, we state the effect of the existence of a rival facility-based firm in a proposition by comparing this case to the case with no such firm, called regime $N$, described in Foros (2004).

Proposition 4 Suppose that an incumbent unilaterally sets the access charge. Then, we have the following.

(i) Firm I in regime NI forecloses firm $S$ if and only if $\gamma \leq \bar{\gamma}$, whereas it always forecloses firm $S$ in regime $\mathrm{N}$.

(ii) Suppose that firm $S$ is accommodated $(\gamma \geq \bar{\gamma})$. Then, the incentives for firm $I$ to invest in infrastructure in regime NI are stronger than that in regime $\mathrm{N}$ if and only if $\gamma<$ $\left(9 s^{2}-10 s+16\right) / 2(2-s)$.

On the other hand, if firm $S$ is foreclosed $(\gamma \leq \bar{\gamma})$, the incentives for firm $I$ to invest in infrastructure are stronger in regime NI than in regime $\mathrm{N}$.

Proof. See Appendix.

The reason for (i) is related to Lemma 2. When firm $F$ exists, firm $I$ is able to use firm $S$ as its affiliate because firm $I$ earns access charge profits from firm $S$. This mitigates the incentives 
for firm $I$ to foreclose firm $S$.

The reason for (ii) (i.e., the investment comparison) is also explained by the mechanism related to Proposition 2. In the case where firm $S$ is accommodated in regime NI, there are three active firms in regime $N I$, whereas there is only one in regime $N$. Firm $I$ 's marginal gain from investment is less sensitive to the level of investment in regime $N$ than in regime $N I$. We can apply the same logic in the discussion of Proposition 2 to that of Proposition 4. Hence, firm $I$ has more incentives to invest in infrastructure in regime $N I$ than in regime $N$ if the investment cost is low but not if the investment cost is high. The strategic effect of spillovers is the same in regime $N I$, as is explained in Proposition 2. The quality improvement effect in regime $N$ is significantly higher than in regime $N I$ because the difference in the number of active firms between regime $N I$ and regime $N(3$ and 1$)$ is larger than that between regime $R I$ and regime $R(3$ and 2$)$.

Similarly, when firm $S$ is foreclosed in regime NI, firm I's marginal gain from investment in regime $N I$ is less sensitive to the level of investment than that in regime $N$ because there are two active firms in regime $N I$ but only one in regime $N$. Since the investment cost is low in the case where a service-based firm's entry is deterred in regime $N I(\gamma<\bar{\gamma})$, firm $I$ always has more incentives to invest in infrastructure in regime $N I$ than in regime $N$ in equilibrium.

\subsection{The effect of access price regulation}

In this subsection, we examine the effect of access price regulation on infrastructure upgrades and foreclosure when there exists a non-incumbent facility-based firm. We obtain the following results.

Proposition 5 (i) Firm I has more incentive to invest in infrastructure in regime NI than in regime RI except in the case where both the degree of spillovers, s, and the investment cost, $\gamma$, are small.

(ii) Firm $F$ has more (less) incentive to invest in infrastructure in regime NF than in regime $\mathrm{RF}$ if $\gamma$ is large (small). 
(iii.1) Firm I has more incentive to invest in infrastructure in regime NIF than in regime RIF except in the case where both s and $\gamma$ are small.

(iii.2) Firm F has more (less) incentive to invest in infrastructure in regime NIF than in regime $\mathrm{RIF}$ if $\gamma$ is large (small).

(iii.3) The total investment level is larger in regime NIF than in regime RIF if $\gamma>4(1-s)$ or if $\gamma$ and $s$ are small enough.

The detail of the conditions is shown in Figure 4.

\section{[Figure 4 here]}

We provide an intuitive explanation for Proposition 5. Basically, the existence of firm $S$ encourages firm $I$ to invest because of the revenue from the access charge. Whenever firm $S$ is accommodated, firm $I$ has more incentive to invest under no access price regulation regimes. When firm $S$ is foreclosed, the strategic effect of firm I's investment is larger under access price regulation regimes because the number of rival firms is larger under those regimes. This effect under access price regulation regimes is stronger when the investment cost and the degree of spillovers are small, that is, when $\gamma$ and $s$ are small, as explained in the previous section.

This logic also applies to the incentives for firm $F$ to invest. That is, firm $F$ has more incentive to invest under access price regulation regimes if $\gamma$ is small, that is, the strategic effect of firm $F$ 's investment is well functioned. When both firms invest and firm $S$ is accommodated, the incentives for firm $F$ to invest become gradually weaker as the degree of spillovers increases (see the fourth panel in Figure 4) because of spillover effects and the strategic substitutability of the investments.

Comparison of social welfare Finally, we examine the effect of access price regulation on social welfare. To do so, we restrict our attention to regimes $R I F$ and $N I F .{ }^{11}$ Due to the

\footnotetext{
${ }^{11}$ The social welfare comparisons between regimes RI and NI or between regimes RF and NF are easily conjectured from the discussion below.
} 
mathematical complexity, we use Figure 5 to discuss social welfare under regimes RIF and NIF. (See Appendix for the derivation of equilibrium profits in both regimes).

[Figure 5 here]

Access price regulation always enhances consumer surplus because it maintains downstream competition. It does not always enhance social surplus, however. In particular, it lowers social surplus in the case where foreclosure would happen if no regulation were imposed. The regulation weakens the incentives for firm $I$ to invest because it is prohibited from earning access charge revenue. As a result, firm $F$ has an incentive to invest more, which distorts the total expenditures on investment. To understand the distortion, we set a targeted total investment level, $\bar{x} \equiv$ $x_{I}+x_{F}$. To achieve the targeted level, the firms expend total investment costs, $I\left(x_{I}\right)+I\left(x_{F}\right)=$ $\gamma\left(x_{I}^{2}+x_{F}^{2}\right) / 2$. The total cost is smaller when the difference between $x_{I}$ and $x_{F}$ is smaller. Thus, distorting the investment levels generates additional costs. Due to this distortion, access price regulation diminishes the social surplus in the white region in Figure 5.

Interestingly, when the investment cost is small enough ( $\gamma$ is small enough), access price regulation enhances the social surplus. Under the access price regulation regime $R I F$, the spillover effect significantly weakens the incentives for firm $I$ to invest because of the strategic substitutability of investments, which implies that firm $F$ has a stronger incentive to invest. As a result, the total investment level under regime $R I F$ is significantly larger than that under regime NIF. This benefit dominates the distortion effect when $\gamma$ is small enough.

\section{Concluding Remarks}

In this paper, we have examined the incentives for firms to make infrastructure upgrades and foreclose service-based firms. We take into account the coexistence of service-based and facility-

based firms. Including both types of firms allows us to examine the structure of "asymmetric access regulation," which is often imposed on incumbent firms in the real world. 
From the analysis, we derived four main results, all of which can be explained by the spillover effect of investments when service-based firms use an incumbent's infrastructure. First, the spillover effect weakens the incumbent's incentives to make infrastructure upgrades regardless of whether access price regulation is imposed on the incumbent or not. However, the spillover effect can also increase the incentives for the incumbent to make infrastructure upgrades if access price regulation is not imposed. Second, the existence of a rival facility-based firm strengthens the incumbent's incentives to make infrastructure upgrades, especially when the spillover effect is large. Third, when there is no access price regulation, the existence of a rival facility-based firm weakens the incumbent's incentives to foreclose a service-based firm. Fourth, the incumbent has more incentives to invest in infrastructure upgrades without access price regulation than with it. On the contrary, a rival facility-based firm can have more incentives to invest in infrastructure upgrades under access price regulation. The last result is explained by the relative magnitudes of the spillover effect and the strategic effect of investments in infrastructure upgrades.

\section{References}

[1] Bender, C. M. and Götz, G., 2011, "Coexistence of Service- and facility-Based Competition: The Relevance of Access Prices for 'Make-or-Buy' Decisions," mimeo.

[2] Bourreau, M. and Doğan, P., 2004, "Service-Based vs. Facility-Based Competition in Local Access Networks," Information Economics and Policy 16, 287-306.

[3] Bourreau, M., Cambini, C. and Doğan, P., 2011, "Incentives to Migrate to Next Generation Networks," mimeo.

[4] Cambini, C. and Jiang, Y., 2009, "Broadband Investment and Regulation: A Literature Review," Telecommunications Policy 33, 559-574. 
[5] Crandall, R., 2005, "Broadband Communications," in S. Majumdar, I. Vogelsang, and M. Cave eds., Handbook of Telecommunications Economics vol. 2, Amsterdam: Elsevier Publishers.

[6] de Bijl, P. and Peitz, M., 2008, "Innovation, Convergence and the Role of Regulation in the Netherlands and Beyond," Telecommunications Policy 32, 744-754.

[7] Foros, Ø, 2004, "Strategic Investments with Spillovers, Vertical Integration and Foreclosure in the Broadband Access Market," International Journal of Industrial Organization 22, $1-24$.

[8] Gans, J., 2001, "Regulating Private Infrastructure Investment: Optimal Pricing for Access to Essential Facilities," Journal of Regulatory Economics 20, 167-198.

[9] Gans, J. and King, S., 2004, "Access Holidays and the Timing of Infrastructure Investment," Economic Record 80, 89-100.

[10] Guthrie, G., 2006, "Regulating Infrastructure: The Impact on Risk and Investment," Journal of Economic Literature 44, 925-972.

[11] Hatfield, D., Mitchell, B., and Srinagesh, P., 2005, "Emerging Network Technologies," in S. Majumdar, I. Vogelsang, and M. Cave eds., Handbook of Telecommunications Economics vol. 2, Amsterdam: Elsevier Publishers.

[12] Hoernig, S., 2011, "Asymmetric Broadband Wholesale Regulation," mimeo.

[13] Huigen, J. and Cave, M., 2008, "Regulation and the Promotion of Investment in Next Generation Networks - A European Dilemma," Telecommunications Policy 32, 713-721.

[14] Kotakorpi, K., 2006, "Access Price Regulation, Investment, and Entry in Telecommunications," International Journal of Industrial Organization 24, 1013-1020. 
[15] Mizuno, K. and Yoshino, Y., 2012, "Distorted Access Regulation with Strategic Investments: Regulatory Non-commitment and Spillovers Revisited," Information Economics and Policy 24, 120-131.

[16] Peitz, M., 2005a, "Asymmetric Access Price Regulation in Telecommunications Markets," European Economic Review 49, 341-358.

[17] Peitz, M., 2005b, "Asymmetric Regulation of Access and Price Discrimination in Telecommunications," Journal of Regulatory Economics 28, 327-343.

[18] Picot, A. and Wernick, C., 2007, "The Role of Government in Broadband Access," Telecommunications Policy 31, 660-674. 


\section{Appendix}

\section{Proof of Proposition 1}

First, we prove (i). We examine the triopoly case in which firm $S$ enters the market. Firm $S$ 's entry condition is $q_{S}\left(x_{I}, x_{F} ; a\right) \geq 0$ or $\alpha+2 c-3 a+(3 s-1) \delta_{I} x_{I}-\delta_{F} x_{F} \geq 0$. In that case, the regulator's problem for setting the optimal access charge in the second stage is given by

$$
\begin{aligned}
& \underset{a}{\operatorname{Max}} W\left(a ; x_{I}, x_{F}\right) \equiv C S+\pi_{I}+\pi_{S}+\pi_{F} \\
& \text { s.t. } a \leq \frac{\alpha+2 c+(3 s-1) \delta_{I} x_{I}-\delta_{F} x_{F}}{3} \equiv \bar{a}^{R}\left(x_{I}, x_{F}\right),
\end{aligned}
$$

where $W\left(a ; x_{I}, x_{F}\right)$ is social welfare in the triopoly. The interior solution of the problem is given by

$$
a^{*}\left(x_{I}, x_{F}\right)=-\alpha+2 c-(11 s-5) \delta_{I} x_{I}+5 \delta_{F} x_{F}
$$

Thus, as long as $\alpha$ is sufficiently large, $a^{*}\left(x_{I}, x_{F}\right)<c<\bar{a}^{R}\left(x_{I}, x_{F}\right)$ because $W\left(a ; x_{I}, x_{F}\right)$ is continuous and concave in $a$. Therefore, under Assumption (i), we have the cost-based access charge, $a^{*}\left(x_{I}, x_{F}\right)=c$, irrespective the innovation regime. Moreover, because $W\left(\bar{a}^{R}\left(x_{I}, x_{F}\right) ; x_{I}, x_{F}\right)=$

$\widetilde{W}\left(x_{I}, x_{F}\right)$, where $\widetilde{W}\left(x_{I}, x_{F}\right)$ is social welfare under a duopoly, we can also verify that the regulator prefers accommodation to foreclosure in any of the three access price regulation regimes.

Second, applying the indicator $\delta_{j} \in\{0,1\}$ to (14) and (15) ensures that $x_{I}^{* R I} \leq x_{F}^{* R F}$ and $x_{I}^{* R I F} \leq x_{F}^{* R I F}$, which proves (ii) and (iii). Similarly, a comparative static exercise ensures (iv). 


\section{Proof of Proposition 2}

We compare $x_{I}^{* R I}$ and $x_{I}^{\# R}$. We have

$$
\begin{aligned}
& x_{I}^{* R I}-x_{I}^{\# R} \\
= & \frac{(3-s) A}{8 \gamma-(3-s)^{2}}-\frac{2(2-s) A}{9 \gamma-2(2-s)^{2}} \\
= & \frac{A \Gamma(\gamma, s)}{\left(8 \gamma-(3-s)^{2}\right)\left(9 \gamma-2(2-s)^{2}\right)} .
\end{aligned}
$$

where $\Gamma(\gamma, s) \equiv-(5-7 s) \gamma+2(3-s)(2-s)$. At $s=0, \Gamma(\gamma, 0) \geq(<) 0$ if and only if $\gamma \leq(>)$ 2.4. Moreover, the threshold $\Gamma(\gamma, s)=0$ is increasing in $s$ on the $(\gamma, s)$ plane for $s \leq 5 / 7$. When $5 / 7<s \leq 1, \Gamma(\gamma, s)>0$ under Assumption (ii). Therefore, we obtain the claim of the proposition.

\section{Proof of Proposition 3}

(i) is already derived in the text. Thus, we show the proofs of (ii) to (iv).

(ii) We compare $x_{I}^{* N I}$ and $x_{F}^{* N F}$. We have

$$
\begin{aligned}
& x_{I}^{* N I}-x_{F}^{* N F} \\
= & \frac{(9+s) A}{22 \gamma-\left(9 s^{2}-14 s+25\right)}-\frac{105 A}{242 \gamma-225} \\
= & \frac{A \Psi(\gamma, s)}{\left(22 \gamma-\left(9 s^{2}-14 s+25\right)\right)(242 \gamma-225)} .
\end{aligned}
$$

where $\Psi(\gamma, s) \equiv 22(11 s-6) \gamma+\left(63 s^{2}-113 s+40\right)$. There are two thresholds $\Psi(\gamma, s)=0$ that are decreasing in $s$ on the $(\gamma, s)$ plane for $\gamma \geq 3 / 2$ and $0 \leq s \leq 1$. See Figure 3.1. Then, we obtain the claim of the proposition.

(iii) We need to compare $x_{I}^{* N I F}$ and $x^{* N I F}$. The same procedure as in (ii) applies to this comparison. See Figure 3.2.

(iv) A comparative static exercise ensure the claim in the proposition. 


\section{Proof of Proposition 4}

(i) In the text, we state that, in Regime $N I$, the necessary and sufficient condition for firm $I$ to accommodate (deter) firm $S$ 's entry is $\gamma \geq(<) 4(1-s)$. Hence, we report the accommodation condition when there is no active facility-based firm in the market. ${ }^{12}$

When firm $F$ is not in the market, the equilibrium quantities in the fourth stage are given by

$$
\begin{array}{ll}
q_{I}\left(x_{I} ; a\right)=\frac{\alpha-2 c+a+(2-s) x_{I}}{3}, & \\
q_{S}\left(x_{I} ; a\right)=\frac{\alpha+c-2 a-(1-2 s) x_{I}}{3}, & \text { under a duopoly, } \\
\widetilde{q}_{I}\left(x_{I} ; a\right)=\frac{\alpha-c+x_{I}}{2}, & \text { under a monopoly. }
\end{array}
$$

In the third stage, firm $S$ enters the market if and only if $q_{S}\left(x_{I} ; a\right) \geq 0$, so that the necessary and sufficient condition for firm $S$ 's entry is given by

$$
\alpha+c-2 a-(1-2 s) x_{I} \geq 0 \text { or } a \leq \frac{1}{2}\left(\alpha+c-(1-2 s) x_{I}\right) \equiv \bar{a}\left(x_{I}\right)
$$

Then, in the second stage, firm $I$ determines the level of access charge by taking its entrydeterrence effect into account. If firm $I$ would like to accommodate firm $S$ 's entry, its problem is

$$
\underset{a}{\operatorname{Max}} \pi_{I}\left(x_{I} ; a\right) \quad \text { s.t. } c \leq a \leq \bar{a}\left(x_{I}\right)
$$

where $\bar{a}\left(x_{I}\right)$ is given by (31). Then, the interior solution of this problem is given by

$$
a^{*}\left(x_{I}\right)=\frac{1}{11}\left(3 \alpha+8 c+(5 s+1) x_{I}\right) .
$$

Because $\pi_{I}\left(x_{I} ; \bar{a}\right)=\widetilde{\pi}_{I}\left(x_{I}\right)$ and $\pi_{I}\left(x_{I} ; a\right)$ is continuous and concave in $a$, firm $I$ accommodates firm $S$ 's entry if and only if $a^{*}\left(x_{I}\right) \leq \bar{a}\left(x_{I}\right)$. Substituting (32) into the inequality $a^{*}\left(x_{I}\right) \leq$

\footnotetext{
${ }^{12}$ See also Foros (2004).
} 
$\bar{a}\left(x_{I}\right)$, we obtain the necessary and sufficient condition for firm $I$ to accommodate firm $S$ 's entry as

$$
6(s-1) x_{I} \geq 0 \text { or } s \geq 1
$$

Otherwise, i.e., $s<1$, firm $I$ deters firm $S$ 's entry, irrespective of the level of $x_{I}$.

Comparing (33) with the condition that $\gamma \geq(<) 4(1-s)$, we have the claim of the proposition.

(ii) We compare $x_{I}^{* N I}$ and $x_{I}^{N}$. We have

$$
\begin{aligned}
& x_{I}^{* N I}-x_{I}^{N} \\
= & \frac{(9+s) A}{22 \gamma-\left(9 s^{2}-14 s+25\right)}-\frac{5 A}{10 \gamma-\left(4 s^{2}-8 s+9\right)} \\
= & \frac{A \Phi(\gamma, s)}{\left(22 \gamma-\left(9 s^{2}-14 s+25\right)\right)\left(10 \gamma-\left(4 s^{2}-8 s+9\right)\right)}
\end{aligned}
$$

where $\Phi(\gamma, s) \equiv 10 \gamma(s-2)-\left(4 s^{3}-17 s^{2}+7 s-44\right)$. At $s=0, \Phi(\gamma, 0) \geq(<) 0$ if and only if $\gamma \leq(>) 2.2$. Moreover, the threshold $\Phi(\gamma, s)=0$ is increasing in $s$ on the $(\gamma, s)$ plane for $\gamma \geq 3 / 2$ and $0 \leq s \leq 1$. Therefore, we obtain the claim of the proposition.

\section{The Derivation of equilibrium profits in regimes $R I F$ and $N I F$}

Regulation regime Substituting (14), (15), and $a=c$ into (2), (3), (4), and (5), we have the equilibrium quantities supplied by the firms:

$$
\begin{aligned}
q_{I}\left(x_{I}^{*}, x_{F}^{*} ; c\right) & =\frac{2 \gamma(2 \gamma-3) A}{16 \gamma^{2}-2\left(9+(3-s)^{2}\right) \gamma+3(3-s)(2-s)}, \\
q_{F}\left(x_{I}^{*}, x_{F}^{*} ; c\right) & =\frac{2 \gamma(2 \gamma-(3-s)) A}{16 \gamma^{2}-2\left(9+(3-s)^{2}\right) \gamma+3(3-s)(2-s)}, \\
q_{S}\left(x_{I}^{*}, x_{F}^{*} ; c\right) & =\frac{(2 \gamma-(3-s)(1-s))(2 \gamma-3) A}{16 \gamma^{2}-2\left(9+(3-s)^{2}\right) \gamma+3(3-s)(2-s)}, \\
Q\left(x_{I}^{*}, x_{F}^{*} ; c\right) & =\frac{\left(12 \gamma^{2}-2(6+(3-s)(2-s)) \gamma+3(3-s)(1-s)\right) A}{16 \gamma^{2}-2\left(9+(3-s)^{2}\right) \gamma+3(3-s)(2-s)} .
\end{aligned}
$$


Using (1), (14), (15), (34), (35), (36), and (37), we have the equilibrium profits of the firms:

$$
\begin{aligned}
\pi_{I}\left(x_{I}^{*}, x_{F}^{*} ; c\right) & =\frac{\gamma(2 \gamma-3)^{2}\left(8 \gamma-(3-s)^{2}\right) A^{2}}{2\left[16 \gamma^{2}-2\left(9+(3-s)^{2}\right) \gamma+3(3-s)(2-s)\right]^{2}}, \\
\pi_{F}\left(x_{I}^{*}, x_{F}^{*} ; c\right) & =\frac{\gamma(2 \gamma-(3-s))^{2}(8 \gamma-9) A^{2}}{2\left[16 \gamma^{2}-2\left(9+(3-s)^{2}\right) \gamma+3(3-s)(2-s)\right]^{2}}, \\
\pi_{S}\left(x_{I}^{*}, x_{F}^{*} ; c\right) & =\frac{(2 \gamma-(3-s)(1-s))^{2}(2 \gamma-3)^{2} A^{2}}{\left[16 \gamma^{2}-2\left(9+(3-s)^{2}\right) \gamma+3(3-s)(2-s)\right]^{2}} .
\end{aligned}
$$

No access price regulation regime When $\gamma>\bar{\gamma}$, we substitute (27), (28), and (29) into (2), (3), (4), and (5) and obtain the equilibrium quantities supplied by the firms:

$$
\begin{aligned}
q_{I}\left(x_{I}^{*}, x_{F}^{*} ; a^{*}\right) & =\frac{(11 \gamma-15)(7 \gamma-(1-s)(1-3 s))(\alpha-c)}{242 \gamma^{2}-\left(225+11\left(25-14 s+9 s^{2}\right)\right) \gamma+15\left(15-11 s+6 s^{2}\right)}, \\
q_{F}\left(x_{I}^{*}, x_{F}^{*} ; a^{*}\right) & =\frac{11 \gamma\left(7 \gamma-\left(10-3 s+3 s^{2}\right)\right)(\alpha-c)}{242 \gamma^{2}-\left(225+11\left(25-14 s+9 s^{2}\right)\right) \gamma+15\left(15-11 s+6 s^{2}\right)}, \\
q_{S}\left(x_{I}^{*}, x_{F}^{*} ; a^{*}\right) & =\frac{(11 \gamma-15)(\gamma-4(1-s))(\alpha-c)}{242 \gamma^{2}-\left(225+11\left(25-14 s+9 s^{2}\right)\right) \gamma+15\left(15-11 s+6 s^{2}\right)}, \\
Q\left(x_{I}^{*}, x_{F}^{*} ; a^{*}\right) & =\frac{\left(165 \gamma^{2}-\left(120+11\left(15-11 s+6 s^{2}\right)\right) \gamma+15(5-3 s)(1-s)\right)(\alpha-c)}{242 \gamma^{2}-\left(225+11\left(25-14 s+9 s^{2}\right)\right) \gamma+15\left(15-11 s+6 s^{2}\right)} .
\end{aligned}
$$

Using (1), (27), (28), (29), (41), (42), (43), and (44), we have the equilibrium profits of the firms:

$$
\begin{aligned}
\pi_{I}\left(x_{I}^{*}, x_{F}^{*} ; a^{*}\right) & =\frac{(11 \gamma-15)^{2}\left(5 \gamma-2(1-s)^{2}\right)\left(22 \gamma-\left(25-14 s+9 s^{2}\right)\right)(\alpha-c)^{2}}{2\left[242 \gamma^{2}-\left(225+11\left(25-14 s+9 s^{2}\right)\right) \gamma+15\left(15-11 s+6 s^{2}\right)\right]^{2}}, \\
\pi_{F}\left(x_{I}^{*}, x_{F}^{*} ; a^{*}\right) & =\frac{\gamma\left(7 \gamma-\left(10-3 s+3 s^{2}\right)\right)^{2}(242 \gamma-225)(\alpha-c)^{2}}{2\left[242 \gamma^{2}-\left(225+11\left(25-14 s+9 s^{2}\right)\right) \gamma+15\left(15-11 s+6 s^{2}\right)\right]^{2}} \\
\pi_{S}\left(x_{I}^{*}, x_{F}^{*} ; a^{*}\right) & =\frac{(11 \gamma-15)^{2}(\gamma-4(1-s))^{2}(\alpha-c)^{2}}{\left[242 \gamma^{2}-\left(225+11\left(25-14 s+9 s^{2}\right)\right) \gamma+15\left(15-11 s+6 s^{2}\right)\right]^{2}} .
\end{aligned}
$$

When $\gamma \leq \bar{\gamma}$, we have the equilibrium quantities supplied by the firms:

$$
q_{j}\left(\widetilde{x}_{I}^{*}, \widetilde{x}_{F}^{*}\right)=\frac{3 \gamma(3 \gamma-4)(\alpha-c)}{27 \gamma^{2}-48 \gamma+16}, Q\left(\widetilde{x}_{I}^{*}, \widetilde{x}_{F}^{*}\right)=\frac{3 \gamma(6 \gamma-8)(\alpha-c)}{27 \gamma^{2}-48 \gamma+16}
$$


The equilibrium profits of the firms are

$$
\pi_{j}\left(\widetilde{x}_{I}^{*}, \widetilde{x}_{F}^{*}\right)=\frac{\gamma(9 \gamma-8)(3 \gamma-4)^{2}(\alpha-c)^{2}}{\left(27 \gamma^{2}-48 \gamma+16\right)^{2}} .
$$




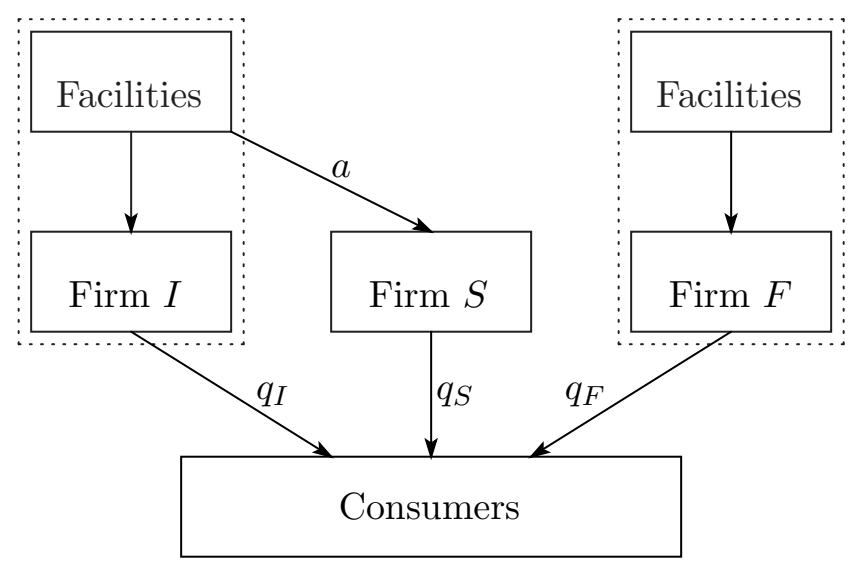

Figure 1: The market structure 


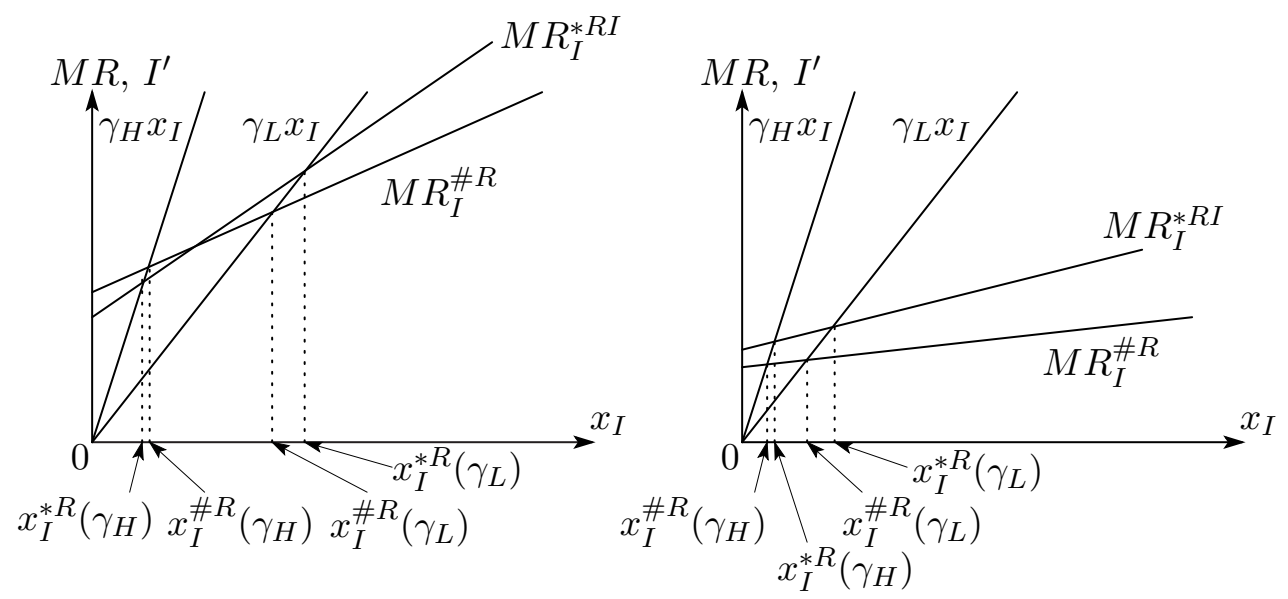

Figure 2: The marginal revenue and the investment cost

Left-hand side: $s=0$; Right-hand side: $s=1$. 


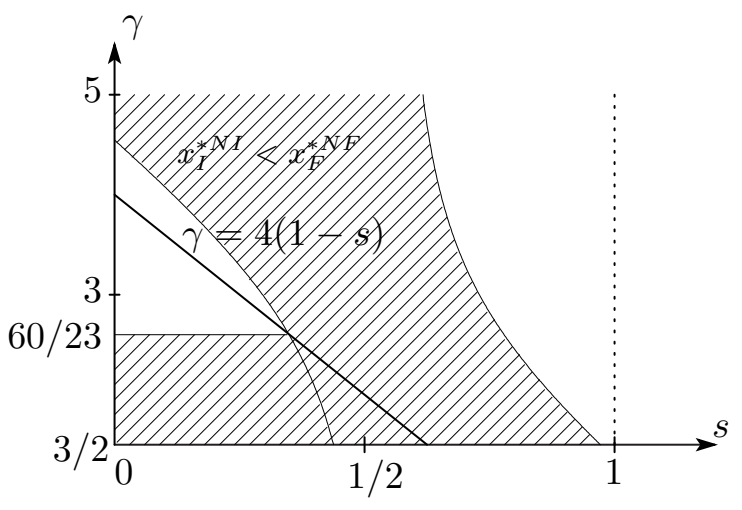

1. The condition in Proposition 3(ii)

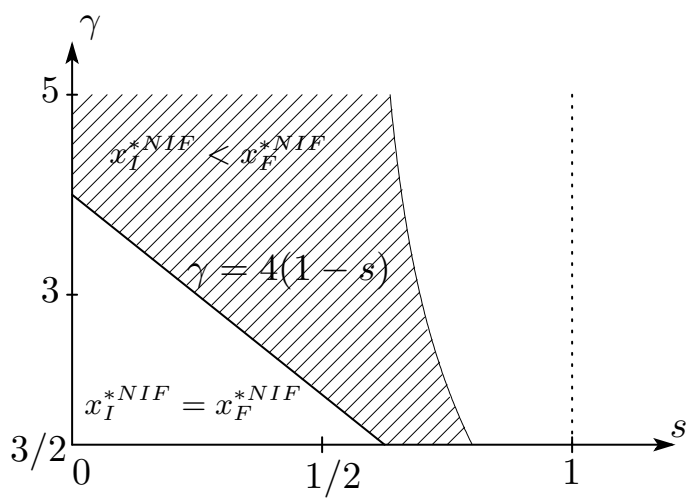

2. The condition in Proposition 3(iii)

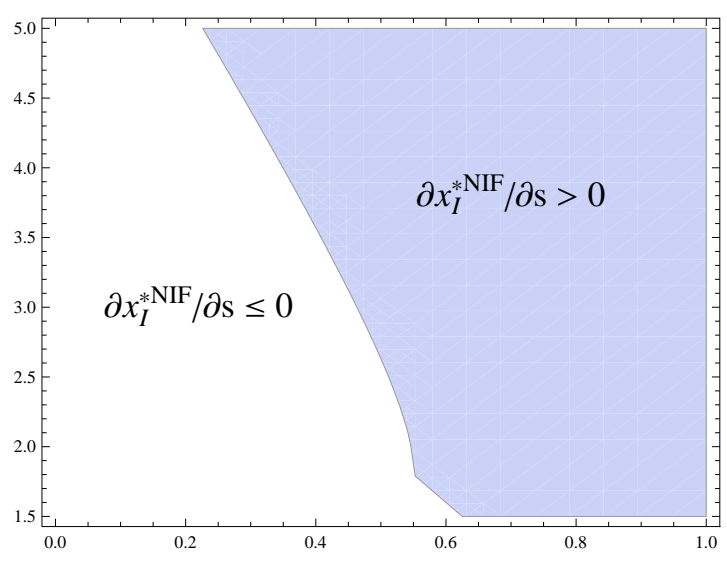

3. The condition that $\partial x_{I}^{* N I F} / \partial s>0$

Figures 3: The conditions in Proposition 3 


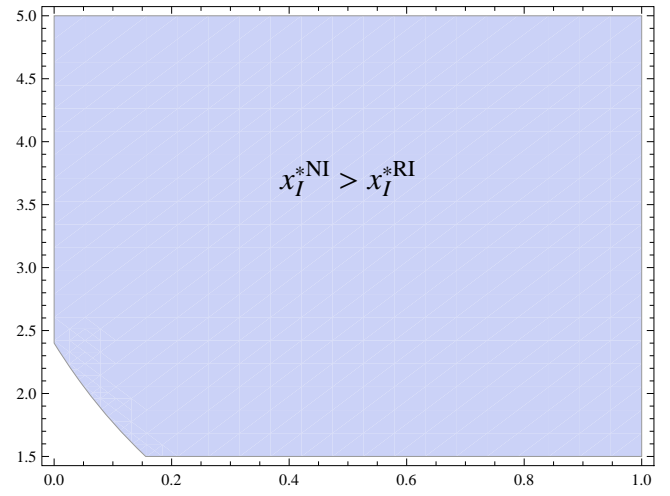

1: The condition in Proposition 5(i)

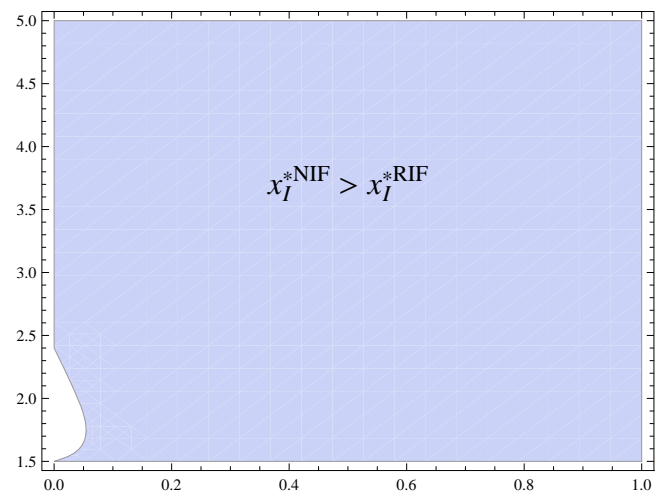

3: The condition in Proposition 5(iii.1)

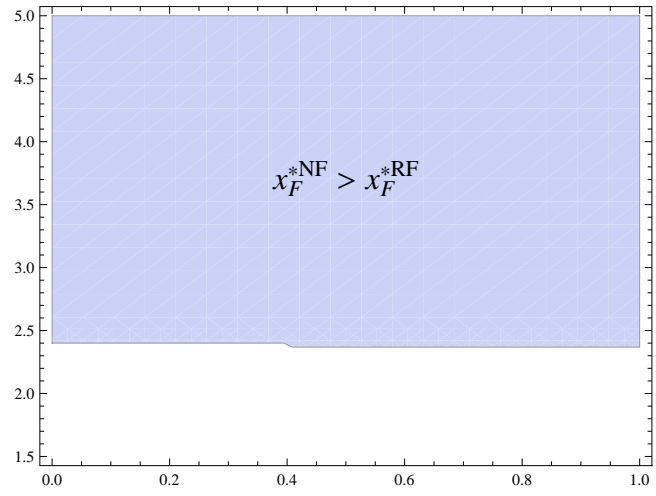

2: The condition in Proposition 5(ii)

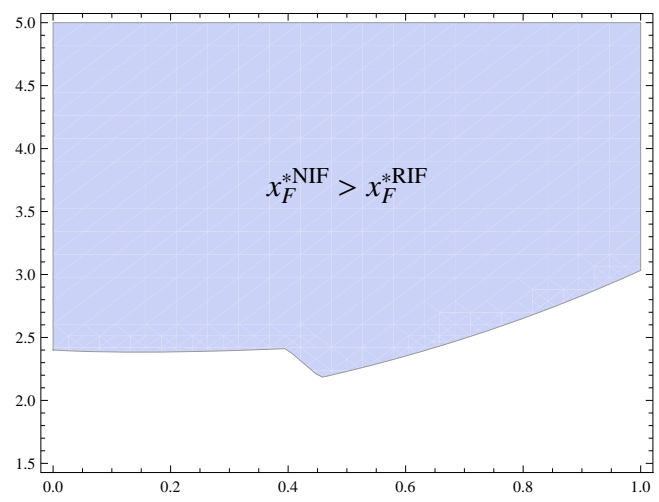

4: The condition in Proposition 5(iii.2)

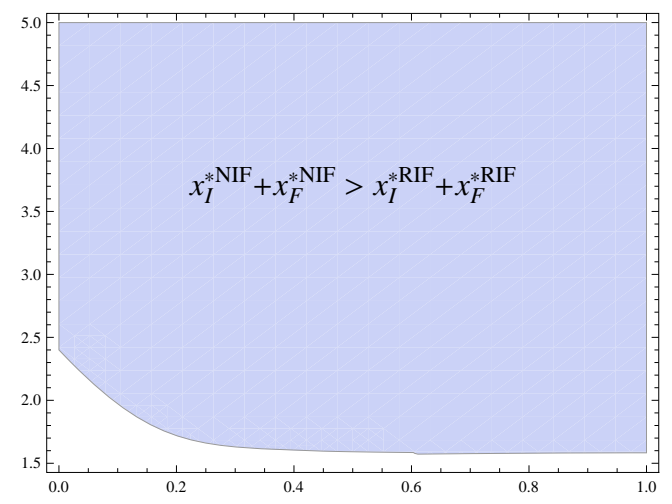

5: The condition in Proposition 5(iii.3)

Figure 4: The conditions in Proposition 5. 


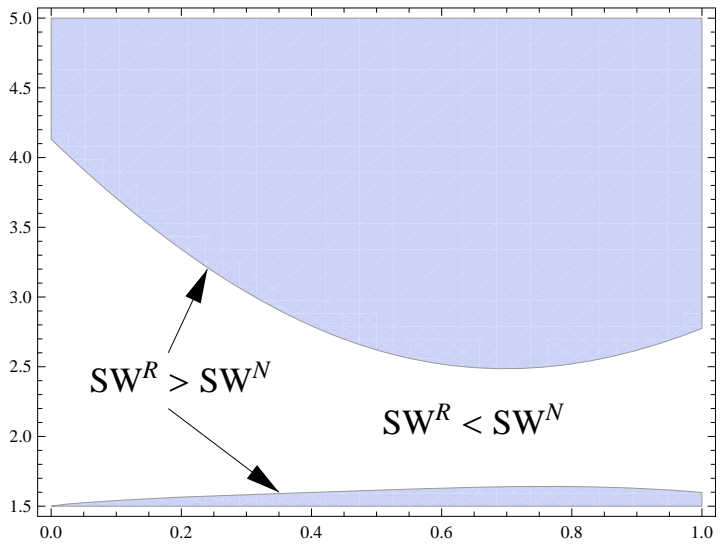

Figure 5: The comparison of social welfare.

Note: $S W^{R}$ and $S W^{N}$ are social welfare in $R I F$ and NIF. 


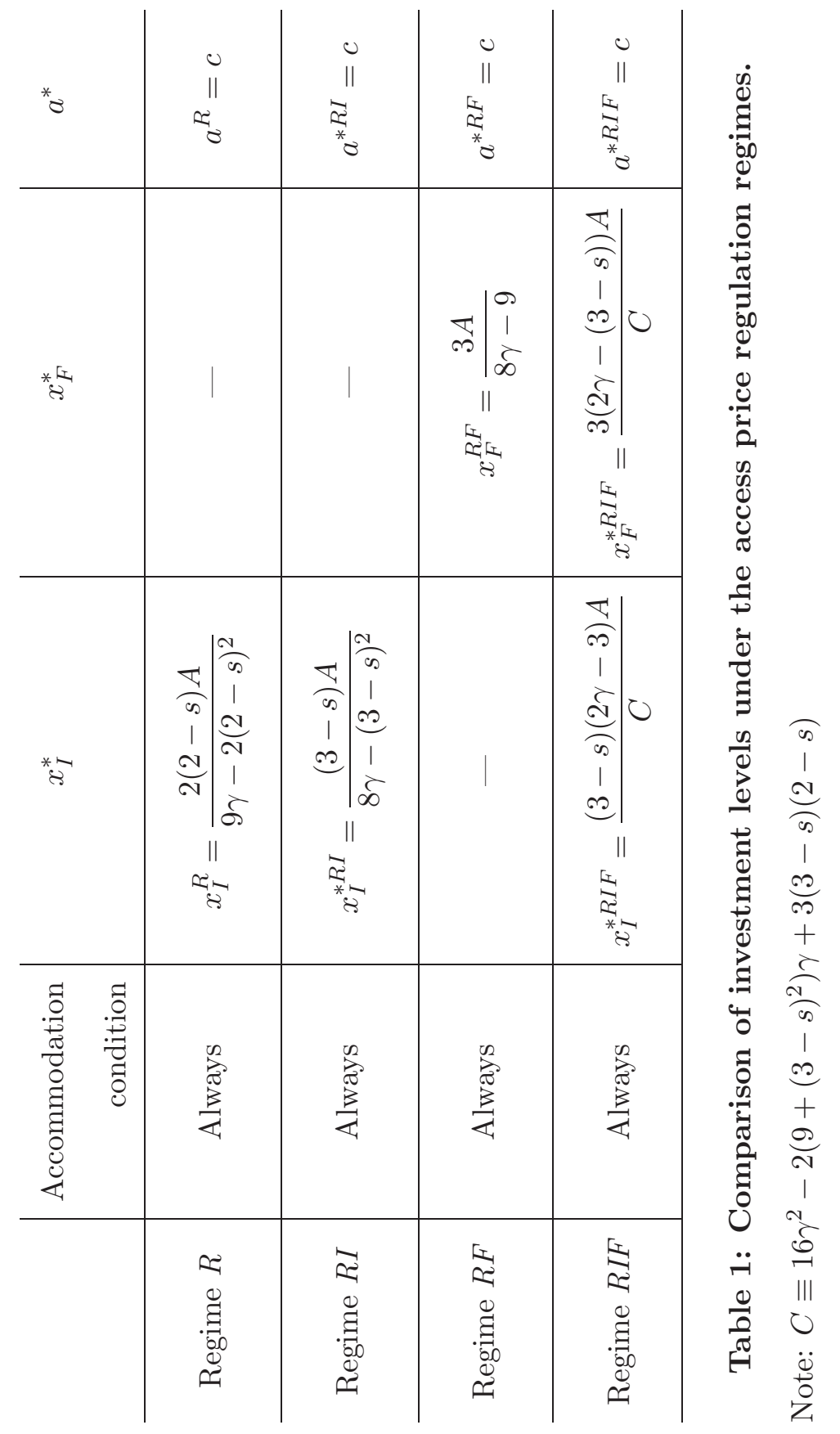




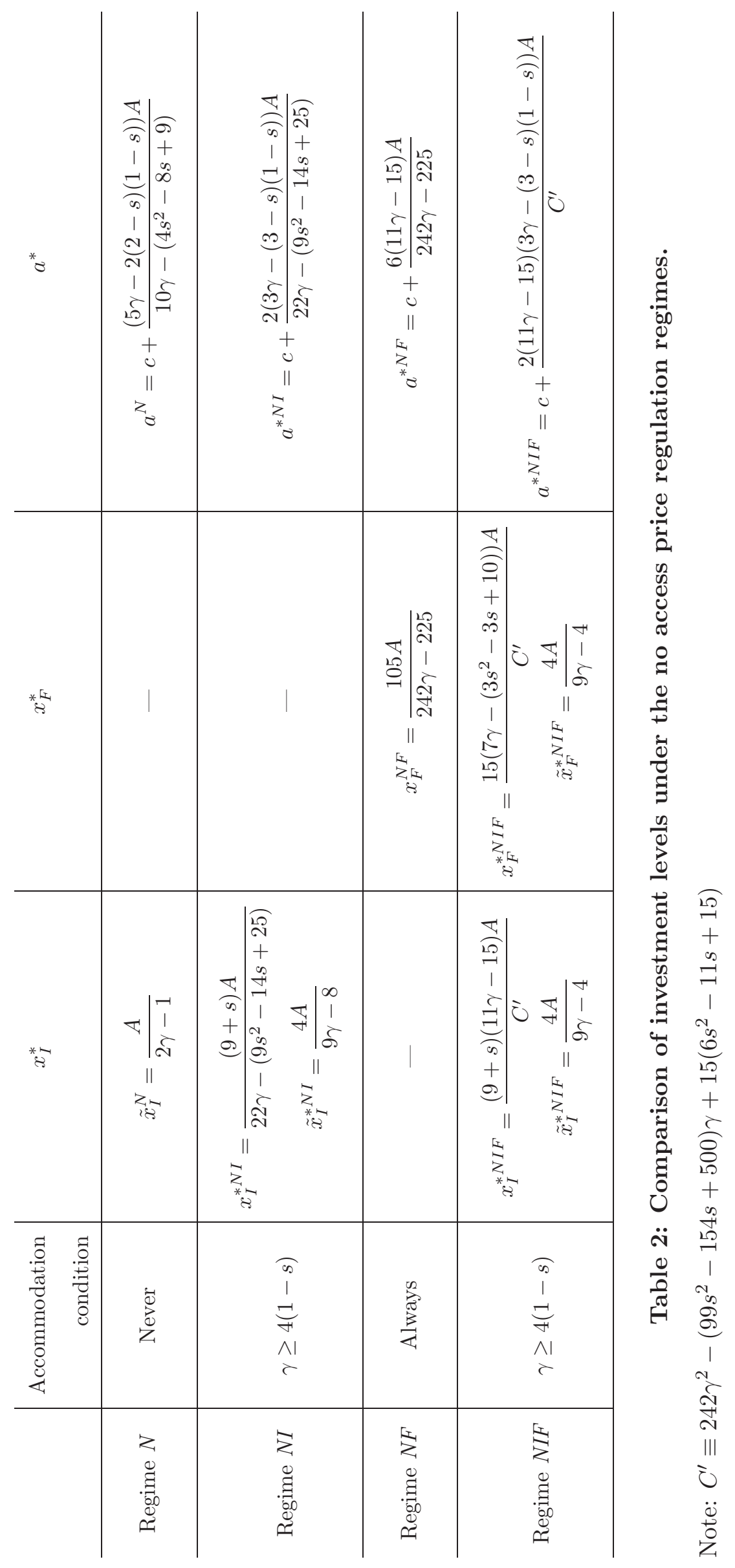

